\begin{tabular}{|l|l|l|}
\hline & \\
PUCRS & HUMANIDADES & $\begin{array}{l}\text { Educação por escrito, Porto Alegre, v. 12, n. 1, p. 1-13, jan.-dez. } 2021 \\
\text { e-ISSN: 2179-8435 }\end{array}$ \\
\hline http://dx.doi.org/10.15448/2179-8435.2021.1.38462 & \\
\hline
\end{tabular}

SECAO: ARTIGOS

\title{
A evasão escolar nos cursos técnicos subsequentes do Instituto Federal do Pará campus Altamira
}

\author{
Evasion in the subsequent technical courses of the Federal Institute of Pará campus \\ Altamira
}

Larici Keli Rocha

Moreira ${ }^{1}$

orcid.org/0000-0001-9565-9948

larici.rocha@ifpa.edu.br

\section{Maria de Fátima Matos \\ de Souza ${ }^{2}$ \\ orcid.org/0000-0003-0214-8941 \\ fmatoz@gmail.com}

\section{Regina Celi Alvarenga de Moura Castro ${ }^{2}$}

orcid.org/0000-0002-8963-3108

reginalmm@yahoo.com.br

Recebido em: 13 junho 2020

Aprovado em: 19 maio 2021

Publicado em: 16 set. 2021.
Resumo: O artigo apresenta os indices de evasão nos cursos técnicos presenciais subsequentes ofertados no Instituto Federal do Pará, campus Altamira, no período de 2010 a 2016, com dados coletados do Sistema Nacional de Informações da Educação Profissional e Tecnológica fornecidos pela Secretaria de Registros e Controle Acadêmico do campus. Foram identificados indices de evasão que variam entre $35,0 \%$ a $84,6 \%$ nos cursos ofertados e um total $61,6 \%$ de evasão no período pesquisado. Os maiores índices de evasão aconteceram nos cursos técnicos em Eventos, 84,6\%, em Redes de Computadores, com 80,0\%, em Restaurante e Bar, com $74,0 \%$ e em Informática para Internet, com $70,5 \%$. Os indices apresentados alertam para a necessidade de um aprofundamento nas discussões sobre a temática, de maneira que o problema seja motivador para a implementação de intervenções institucionais locais, capazes de modificar essa realidade com a sensibilização e comprometimento de toda a comunidade escolar.

Palavras-chave: Ensino técnico. Permanência. Políticas públicas.

Abstract: The study presents dropout rates in subsequent technical courses at Federal Institute of Pará - Altamira, from 2010 to 2016, with information about the National Information System for Vocational and Technological Education provided by the Campus Records and Academic Control Secretariat. Dropout rates ranging from $35.0 \%$ to $84.6 \%$ were identified in the following courses and a total of $61.6 \%$ school evasion in the investigated period. The highest drop out rates happened in the technical courses in Events, 84.6\%, Computer Networks, with $80.0 \%$, Restaurant and Bar, $74.0 \%$ and Internet Computing, 70.5\%. The indices reported warn of the need of discussions about it. Then, the present essay motivates the implementation of local institutional interventions, able to change this reality with the awareness and commitment of the whole school community. Keywords: Technical education. Permanence. Public policy.

\section{Introdução}

Neste artigo é estabelecida uma discussão que se insere no contexto de discussão sobre a evasão na educação profissional tecnológica (EPT) no Brasil, tendo como locus de investigação o Instituto Federal do Pará, Campus Altamira.

O ensino técnico brasileiro foi marcado pela criação, em 1909, de instituições voltadas para a formação de aprendizes e artífices e a sua origem traz a oferta de educação destinada "às classes menos favorecidas" (BRASIL, 1937, p. 25). Desde então, em seus 110 anos de existência, tem sido pauta- 
do, entre outros aspectos, por alterações em sua estrutura, em sua terminologia e pelas instituições que ofertam essa modalidade de ensino, assunto aprofundado na segunda seção desse artigo.

No estado do Pará, onde se deu essa pesquisa, o Instituto Federal foi criado em 2008 pela integração do Centro Federal de Educação Tecnológica do Pará (CEFET-PA) e das Escolas Agrotécnicas Federais de Castanhal (EAFC) e de Marabá (EAFMB) (IFPA, 2014). Possui uma estrutura de 18 campi localizados em todas as regiões do estado e tem como missão a promoção da EPT "em todos os níveis e modalidades por meio do ensino, pesquisa, extensão e inovação para o desenvolvimento regional sustentável, valorizando a diversidade e a integração dos saberes" (IFPA, 2014, p. 19).

O Instituto Federal do Pará, campus Altamira, localizado na região sudoeste do estado, no municipio de Altamira, atende os estudantes dos municípios de Altamira, Anapú, Brasil Novo, Medicilândia, Pacajá, Placas, Porto de Moz, Senador José Porfírio, Uruará e Vitória do Xingu (IFPA, 2015), com a oferta de cursos de formação inicial e continuada, técnicos integrados e subsequentes, tecnólogo superior e de pós-graduação.

A EPT, assim como em todos os níveis e modalidades da educação brasileira enfrenta problemas relacionados à evasão escolar, que requerem uma atenção especial no interior das instituições. Por isso, tem sido um tema discutido no âmbito da literatura científica brasileira. Especificamente na EPT, autores como Castro e Malacarne (2011); Dore e Luscher (2011); Araújo e Santos (2012); Falcão e Sansil (2014); Souza (2014); e Silva Filho e Araújo (2017), dentre outros, abordam essa temática.

Contudo, foi a partir da grande expansão da educação profissional, científica e tecnológica, vivenciada a partir da década de $2010^{2}$ que estudos nessa área cresceram, por ter sido identificado pelo Ministério da Educação (MEC) e no interior das instituições que, concomitante ao aumento de ingressantes, houve aumento do índice de evasão, sendo equiparado em algumas instituições a quase totalidade do índice de concluintes ao número de alunos evadidos (BRASIL, 2014).

Nesse sentido, a expansão na oferta de vagas na EPT, acentuou o campo da discussão científica sobre a evasão nessa modalidade de ensino. É nesse contexto de discussão que se delimita a questão central deste estudo: Qual foi o índice de evasão ocorrida nos cursos técnicos subsequentes presenciais ofertados no periodo de 2010 a 2016 no Instituto Federal de Educação, Ciência e Tecnologia do Pará (IFPA) campus Altamira?

Para melhor delimitação do campo de pesquisa foram considerados dados dos cursos presenciais ofertados somente no municipio de Altamira, uma vez que no período pesquisado, o campus ofertou cursos presenciais também nos municipios de Brasil Novo, Vitória do Xingu e Porto de Moz, além da oferta por meio da educação a distância.

Os cursos, objetos de investigação, foram os técnicos ofertados na modalidade subsequente no campus Altamira no periodo compreendido entre os anos de 2010 a 2016: cursos em Aquicultura, Edificações, Eventos, Meio Ambiente, Informática, Informática para Internet, Pesca, Redes de Computadores, Serviços de Restaurante e Bar e Saneamento.

A justificativa de eleger a modalidade de curso subsequente presencial como foco desta investigação, se deu pelo fato de que no período delimitado para a pesquisa, o campus Altamira obtinha sua maior oferta voltada para cursos técnicos dessa modalidade.

Este estudo foi realizado por meio da abordagem quanti-qualitativa da pesquisa, tendo como técnicas para coleta de dados a revisão de literatura e a análise documental.

Segundo Gil (2010) a revisão de literatura fornece ao trabalho uma fundamentação teórica atual com base nos materiais já publicados sobre o tema proposto, tornando-se indispensável a contextualização histórica sobre o objeto de estudo.

A análise documental foi realizada para identificação dos dados relacionados ao ingresso, conclusão e evasão escolar fornecidos pela Secretaria de Registros e Controle Acadêmico (SRCA) do campus Altamira que são armazenados 
no Sistema Nacional de Informações da Educação Profissional e Tecnológica (SISTEC), programa do governo federal, cujo objetivo é a realização do registro e controle dos dados de oferta da EPT no país (BRASIL, 2016c), no periodo pesquisado.

O conceito de evasão adotado nesse estudo se apoiou na definição delimitada pelo Instituto Nacional de Estudos e Pesquisas Educacionais Anísio Teixeira (INEP, 1998), como sendo a evasão a saída definitiva do aluno do ambiente escolar. Essa conceituação tem sido recorrente também na literatura quando a discussão diz respeito ao abandono, pelo aluno, de determinada instituição de ensino.

Este artigo está organizado em quatro seções: a primeira, na qual é apresentada a metodologia; a segunda, destinada ao breve histórico da EPT no Brasil; a terceira, na qual são demonstrados os aspectos relacionados à evasão na EPT a luz de autores e; a quarta se destina à apresentação e análise dos dados referentes aos índices de evasão nos cursos técnicos subsequentes presenciais ofertados pelo IFPA Campus Altamira no período de 2010 a 2016.

\section{Breve histórico da educação profissional e tecnológica no Brasil}

As primeiras escolas técnicas do Brasil foram criadas no ano de 1909 sob a designação de Escolas de Aprendizes e Artífices, instituições que foram destinadas "ao ensino profissional primário e gratuito" (BRASIL, 1909, p. 1), por meio do decreto $n .^{\circ} 7.566$, voltadas para as classes mais populares, com a justificativa de "afastar os pobres e desvalidos de fortuna da ociosidade do vício e do crime. Esta visão foi dominante até o estabelecimento do projeto de industrialização a partir de 1930" (CAMPOS, 2016, p. 4).

Na década de 1930 as Escolas de Aprendizes e Artífices foram transformadas em Liceus por meio da Lei n. ${ }^{\circ}$ 378, de 1937, dando-lhes a missão de ofertar o "ensino profissional em todos os ramos e graus" (BRASIL, 1937a, p. 9).

Na década seguinte, em 1942, houve uma organização da rede federal de educação por meio do Decreto n. ${ }^{\circ}$ 4.127, no qual os antigos Liceus passaram a ser Escolas Industriais e Técnicas, autarquias com autonomia didática e de gestão, vinculadas a administração do Ministério da Educação (BRASIL, 1942, p. 1). Em 1959, passam por nova reformulação e também recebem nova nomenclatura, "Escolas Técnicas Federais", e assumem o objetivo de formar técnicos e impulsionar a industrialização do país (BRASIL, 2016b).

Em 1978, duas Escolas Técnicas Federais, a de Minas Gerais e do Paraná foram transformados em Centros Federais de Educação Tecnológica (CEFET), como uma nova experiência para a formação de engenheiros de operação e de cursos tecnólogos (BRASIL, 1978, p. 1). Duas décadas depois, por ter sido as experiências mineiras e paranaenses consideradas exitosas pelo MEC, as demais Escolas Técnicas Federais passaram a assumir a estrutura de CEFET, compondo o Sistema Nacional de Educação Tecnológica, instituído pela Lei n. ${ }^{\circ}$ 8.948, de 8 de dezembro de 1994 (BRASIL, 1994).

Contudo, o marco da transformação na base legal da EPT no Brasil aconteceu no ano de 2008, a partir da inserção na Lei n. ${ }^{\circ}$ 9.394/96 de Diretrizes e Bases da Educação Nacionais (LDB) de um capítulo específico para a educação profissional integrando-a aos diferentes "niveis e modalidades da educação e as dimensões do trabalho, da ciência e da tecnologia" [com a oferta de cursos] "I - de formação inicial e continuada ou qualificação profissional; II - de educação profissional técnica de nivel médio; III - de educação profissional tecnológica de graduação e pós-graduação" (BRASIL, 2008, p. 16).

Nesse mesmo ano foi instituida a Rede de Educação Profissional, Científica e Tecnológica, composta pelos Institutos Federais de Educação, Ciência e Tecnologia (IF), pela Universidade Tecnológica Federal do Paraná (UTFPR), pelos Centros Federais de Educação Tecnológica Celso Suckow da Fonseca (CEFET-RJ) e de Minas Gerais (CEFET-MG), pelas Escolas Técnicas Profissionalizantes vinculadas às instituições federais e pelo Colégio Pedro II (BRASIL, 2008b), do Rio de Janeiro.

Com a organização da Rede de Educação Profissional, Científica e Tecnológica, o número de instituições que ofertam o ensino técnico no Brasil, teve um aumento significativo (Figura 1). 
Figura 1 - Expansão da Rede Federal de Ensino Profissionalizante em números no Brasil

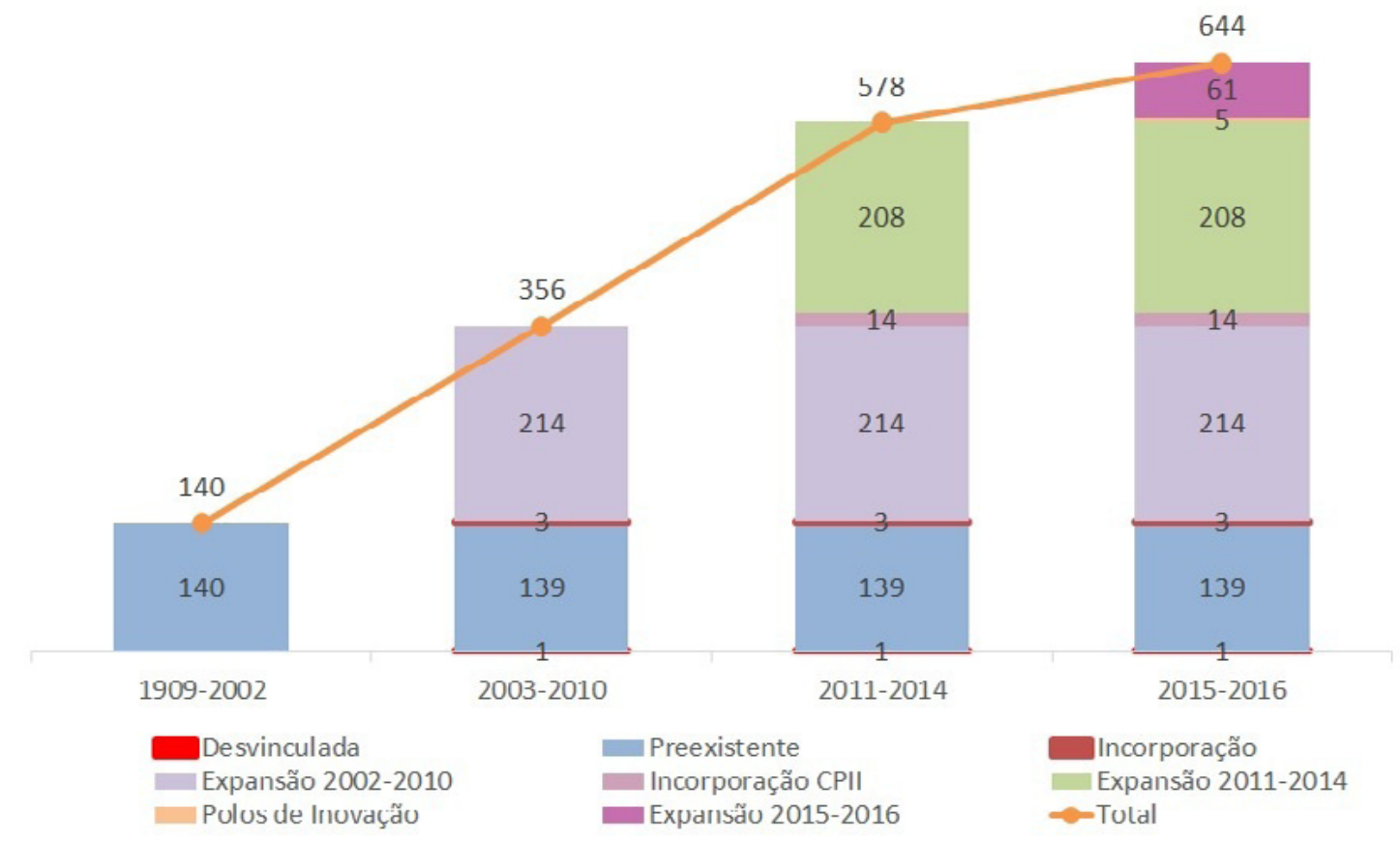

Fonte: BRASIL (2016).

Desde a criação das Escolas de Aprendizes e Artífices, as escolas técnicas na rede federal, atingiram a marca de 644 instituições em 2016 com a expansão da Rede de Educação Profissional, Cientíica e Tecnológica (BRASIL, 2016a).

No estado do Pará, conforme já fora mencionado, o IF foi criado no ano de 2008 e atende além de Altamira, nove municípios da região sudoeste do estado.

A instituição da rede federal proporcionou uma expansão significativa no número de escolas técnicas na rede. Se ao final de 2002, o Brasil tinha 140 escolas, passa a 356 em 2010, o que representa crescimento de 154,3\% em oito anos. Em 2014, já eram 578 escolas técnicas na rede, o que indica aumento de $62,4 \%$ nesse intervalo de quatro anos. Atinge 644 escolas técnicas em 2016 (BRASIL, 2016a), resultando no aumento de 11,4\% nesses dois anos. No intervalo que compreende o período de 2002 a 2016, o crescimento de escolas técnicas na rede foi de 360,0\%. Esse acelerado crescimento, ocasionou também um aumento da evasão nesse meio. Sobre as causas que levaram à evasão, nesse contexto, são apresentados a seguir resultados de pesquisas realizadas na atual década, no meio científico brasileiro.

\section{Aspectos gerais que tratam da evasão} no contexto da EPT

A evasão está presente em todos os niveis e modalidades de ensino. Para compreender os motivos que levam o aluno a abandonar a escola, torna-se necessário compreender a grande complexidade de fatores que circundam as relações, o universo e as condições em que se dá o processo educacional em cada ambiente formativo (MACHADO, 2009). Buscou-se em autores brasileiros que realizaram pesquisas sobre as causas da evasão na EPT, fundamentação para compreender as razões que podem levar os estudantes a abandonarem seus estudos.

Sobre as causas da evasão, Bastos e Gomes (2014) indicam que o ato final da saída da escola revela um processo que, visivel ou não, se manifesta de variadas formas no decorrer da vida escolar, podendo ser influenciada por fatores internos e externos ao contexto educacional. Pode ser oriunda de fatores relacionados a ordem pessoal ou institucional, ou ainda por ambos. Silva Filho e Araújo (2017, p. 36) ao discorrerem 
sobre os fatores internos e externos que levam a evasão escolar, explicitam que:

drogas, tempo na escola, sucessivas reprovações, falta de incentivo da familia e da escola, necessidade de trabalhar, excesso de conteúdo escolar, alcoolismo, localização da escola, vandalismo, falta de formação de valores e preparo para o mundo do trabalho, podem ser considerados decisivos no momento de ficar ou sair da escola, engrossando a fila do desemprego.

Bastos e Gomes (2014) ao realizarem uma pesquisa nos cursos técnicos concomitantes ofertados no Centro Federal de Educação Tecnológica do Rio de Janeiro (CEFET/RJ), verificam como causas da evasão: desmotivação, necessidade de trabalhar e dificuldade em conciliar trabatho e estudo, deficiências no processo ensino aprendizagem com professores despreparados, a violência entre estudantes, problemas de saúde e gravidez durante o curso.

Sobre a evasão no Instituto Federal de Educação, Ciência e Tecnologia do Rio Grande do Norte (IFRN), Campus São Gonçalo do Amarante, Souza (2014) observa que, um dos principais fatores destacados pelos estudantes que compromete a sua permanência nos cursos, é a distribuição das disciplinas no currículo escolar, algumas de difícil compreensão.

Acerca da dificuldade dos estudantes relacionadas ao currículo escolar, Araújo e Santos (2012) sugerem que dentre as ações para minimizar os indices de evasão na educação profissional, deva estar a adequação do currículo e sua relação com o mundo do trabalho. Currículo desatualizado com metodologias tradicionais de ensino, estrutura engessada e recursos defasados têm sido fatores motivacionais para a evasão escolar, segundo os autores.

Ao analisar a EPT e sua estrutura curricular, Falcão e Sansil (2014), explicitam que é preciso que o currículo e a metodologia desenvolvida no interior das instituições de ensino estejam articulados com os avanços e as transformações sociais e tecnológicas do mundo produtivo, de modo que os profissionais sejam capazes de se posicionarem frente a essas mudanças de maneira crítica e autônoma.

Nesse sentido, Ferreira (2013) esclarece que a escola, por vezes não é atrativa, mantém professores despreparados e há ausência de motivação. Nesse cenário surge, ainda, o desinteresse pelo acompanhamento dos filhos por parte da família, a dificuldade em conciliar horário de trabalho com os estudos e as dificuldades de convivência em grupo, como fatores que contribuem para que a evasão aconteça.

Dore e Luscher (2011) ao realizarem uma pesquisa no âmbito do Programa de Educação Profissional de Minas Gerais, observaram como principais causas da evasão nos cursos técnicos, o ingresso em nível superior, a necessidade de trabalho, a não identificação com o perfil do curso, falta de transporte, dificuldades no processo de aprendizagem, saúde e gravidez.

Ao discutirem os fatores que levam à evasão sob a ótica escolar, as autoras revelam que "a composição do corpo discente, os recursos escolares, as características estruturais da escola, e os processos e as práticas escolares e pedagógicas" (DORE; LUSCHER, 2011, p. 777) são fatores que se ramificam em muitos outros e podem ser decisivos quanto ao desempenho acadêmico. Dessa forma, as questões didático-pedagógicas devem ser alvo constante de atenção das instituições.

No estudo de caso sobre as causas da evasão no CEFET/RJ Unidade Descentralizada de Petrópolis, Figueiredo e Salles (2017) identificaram como fatores determinantes para a evasão: a dinâmica das aulas, a falta de flexibilidade de horários, a falta de incentivo por parte dos professores, o acúmulo de avaliações em um mesmo período, a falta de conhecimentos anteriores, a dificuldade de conciliar o curso com atividades extras, incluindo as laborais, e a frustração diante dos desafios impostos no meio escolar. Também são evidenciados na pesquisa, que a evasão pode ser promovida pela oportunidade de conseguir um trabalho e, que há falta de interesse da própria instituição em efetivar políticas públicas eficazes para minimizar os índices de evasão (FIGUEIREDO; SALLES, 2017).

Com foco na pesquisa sobre evasão nos cursos de Agropecuária e de Informática da Escola Agrotécnica Federal de Inconfidentes, MG, Machado (2009) constatou que o fator socioeconômico tem 
influência na decisão pela evasão ou permanência no curso. No estudo foi identificado que, dentre os motivos principais da evasão estão as dificuldades com o processo de ensino aprendizagem, o excesso de conteúdo e a necessidade de trabalho.

No campus Cariacica do Instituto Federal do Espírito Santo (IFES), mais especificamente no curso Técnico em Ferrovias, ofertado na modalidade concomitante ao ensino médio, Meira (2015) detectou na entrevista com estudantes evadidos que os principais motivos que levam à evasão estão os relacionados à falta de perspectiva de emprego na área do curso, a aprovação em curso superior, a dificuldade em conciliar trabalho e estudo, a dificuldade de conseguir assimilar os conteúdos ministrados e, apesar da dedicação nos estudos, o baixo rendimento acadêmico.

Com o objetivo de promover a permanência estudantil, em 2010 o governo federal criou, por meio do Decreto n. ${ }^{\circ}$ 7.234, de 19 de julho, o Plano Nacional de Assistência Estudantil (PNAES), um programa de assistência estudantil voltado para a ampliação das "condições de permanência dos jovens na educação superior pública federal". O programa tem, dentre os objetivos, a democratização das condições de permanência, a redução das taxas de retenção e evasão e a promoção da inclusão social pela educação (BRASIL, 2010, p. 1).

Dessa forma, o decreto prevê que as ações de assistência estudantil devem atender estudantes advindos de escola pública que possuem renda de até um salário-mínimo e meio e, que cada instituição federal defina os critérios de seleção dos estudantes, bem como o acompanhamento e avaliação do programa. Os recursos são distribuidos para as instituições que além de gerenciá-los, devem prestar contas ao MEC. A assistência estudantil realizada contempla a concessão de bolsas em diversas áreas, como alimentação, moradia, transporte, cultura, esporte, apoio pedagógico, atenção à saúde, acesso e aprendizagem de estudantes com deficiência e inclusão digital (BRASIL, 2010). Dessa forma, a assistência estudantil contribui no combate à evasão, uma vez que auxilia na melhora das condições de ensino e desempenho dos estudantes.

A Secretaria de Educação Profissional e Tecnológica (SETEC), responsável pela supervisão da educação tecnológica e profissionalizante divulgou dados de evasão na rede federal no período de 2009 a 2013, indicando que acompanhada da ampliação das vagas, houve um aumento significativo da evasão, em um quantitativo quase equiparado ao crescimento do número de ingressantes no período, o que acentuou a preocupação com a evasão nesse contexto. O aumento de vagas acarretou o aumento de aproximadamente $300,0 \%$ no número de matriculados (Figura 2).

Figura 2 - Evolução do número de ingressantes, matriculados, concluídos e evadidos em cursos ofertados pela Rede Profissional, Científica e Tecnológica, no período de 2009 a 2013

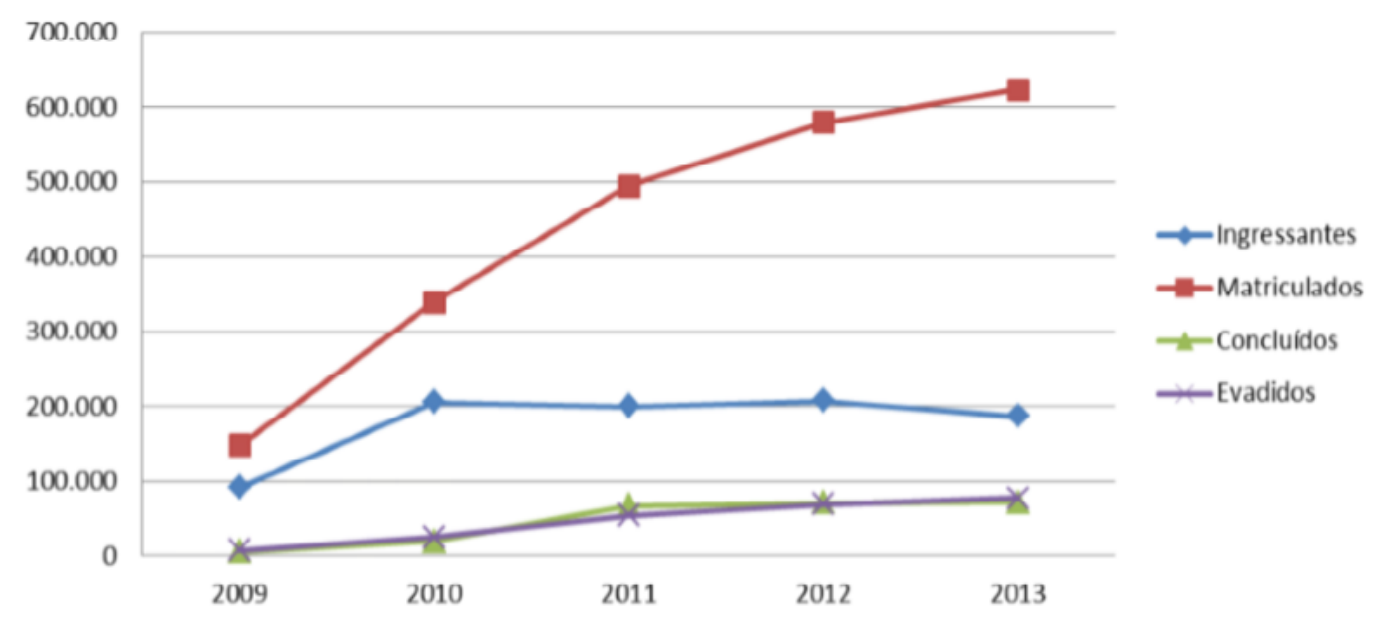

Fonte: SETEC/MEC (BRASIL, 2014). 
A partir dessa constatação a SETEC lançou um documento orientador para a superação da evasão e retenção na rede federal de ensino profissionalizante.

O documento consiste em um plano de ação com objetivo de "orientar o desenvolvimento de ações capazes de ampliar as possibilidades de permanência e êxito dos estudantes no processo formativo" (BRASIL, 2014, p. 4).

Como medidas de enfrentamento à evasão e retenção no documento é orientado que cada instituição "elabore e desenvolva um Plano Estratégico de Intervenção e Monitoramento para Superação da Evasão e Retenção" (BRASIL, 2014, p. 29), que tenha como foco o diagnóstico sobre as causas da evasão e conste ações que "contribuam para o enfrentamento da evasão e retenção em todos os níveis e modalidades da oferta educacional" (BRASIL, 2014, p. 28).

No IFPA as ações relacionadas à permanência e ao êxito estudantil são trabalhadas desde 2015. conforme publicação no site oficial da instituição. Os trabalhos são realizados pela Comissão de Permanência e Exxito Institucional, que desenvolve junto aos campi, ações voltadas para o diagnóstico das causas da evasão, bem como para a diminuição da retenção nos cursos (IFPA, 2017).

A indicação da evasão como um problema complexo, alerta para a relevância de se identi- ficar os fatores que ocasionam esse fenômeno, com vistas à elaboração de estratégias de acompanhamento institucional bem definidas, com implementação de políticas de enfrentamento que visem a permanência e êxito acadêmico.

Contudo, não há ainda estudos publicados sobre as causas da evasão no campus Altamira, porém os dados identificados nesse estudo, apresentados na próxima seção, poderão fomentar futuras pesquisas destinadas a constatar as causas da evasão a partir dos estudantes evadidos.

\section{A evasão escolar nos cursos subsequentes do IFPA campus Altamira no período de 2010 A 2016}

Nessa seção são apresentados dados quantitativos absolutos e percentuais sobre o número de alunos concluintes e evadidos nos dez cursos ofertados na modalidade técnico subsequente presencial pelo campus Altamira, no periodo compreendido entre os anos de 2010 e 2016 , conforme pode ser observado na Tabela 1.

Ressalta-se que no ano de 2014, a oferta de cursos técnicos do IFPA campus Altamira foi realizada apenas na modalidade à distância, fato que justifica ausência desse ano na Tabela 1.

TABELA 1 - Número de alunos evadidos e concluídos nos cursos técnicos subsequentes presenciais ofertados pelo IFPA campus Altamira de 2010 a 2016 e total no período

\begin{tabular}{|c|c|c|c|c|c|c|c|c|c|c|c|c|c|c|}
\hline \multirow{2}{*}{ CURSO } & \multicolumn{2}{|c|}{2010} & \multicolumn{2}{|c|}{2011} & \multicolumn{2}{|c|}{2012} & \multicolumn{2}{|c|}{2013} & \multicolumn{2}{|c|}{2015} & \multicolumn{2}{|c|}{2016} & \multicolumn{2}{|c|}{ Total } \\
\hline & $E$ & C & $E$ & C & $E$ & C & $E$ & C & $E$ & C & $\mathbf{E}$ & C & $E$ & C \\
\hline Aquicultura & 20 & 10 & 17 & 17 & - & - & - & - & - & - & - & - & 37 & 27 \\
\hline Edificações & 23 & 17 & 18 & 22 & 39 & 41 & 25 & 15 & 66 & 14 & 26 & 12 & 197 & 121 \\
\hline Eventos & - & - & 32 & 7 & 34 & 5 & - & - & - & - & - & - & 66 & 12 \\
\hline Informática & 16 & 14 & 21 & 9 & - & - & 15 & 15 & 45 & 15 & 7 & 21 & 104 & 74 \\
\hline $\begin{array}{l}\text { Informática para } \\
\text { Internet }\end{array}$ & - & - & 18 & 13 & 25 & 5 & - & - & - & - & - & - & 43 & 18 \\
\hline Meio Ambiente & 15 & 25 & 13 & 27 & - & - & - & - & - & - & - & - & 28 & 52 \\
\hline Pesca & 13 & 13 & - & - & - & - & & - & - & - & - & - & 13 & 13 \\
\hline Restaurante e Bar & 12 & 2 & 25 & 11 & - & - & - & - & - & - & - & - & 37 & 13 \\
\hline $\begin{array}{l}\text { Redes de } \\
\text { Computadores }\end{array}$ & - & - & - & - & 24 & 6 & - & - & - & - & - & - & 24 & 6 \\
\hline Saneamento & 21 & 19 & - & - & - & - & - & - & - & - & - & - & 21 & 19 \\
\hline
\end{tabular}

Fonte: Secretaria de Registros e Controle Acadêmico - IFPA campus Altamira (2019). Número de alunos evadidos (E) e concluídos (C). 
No periodo pesquisado, os cursos técnicos em Edificações e em Informática foram os cursos com maior oferta de vagas com ingresso de 496 estudantes, desses, somente 195 concluiram o curso, o que indica 301 estudantes evadidos, o que representa $60,7 \%$ de evasão. Dos 496 estudantes, 318 foram em Edificações e 178 em Informática, com 61,9\% de evasão em Edificações e $58,4 \%$ de evasão em Informática.
Os cursos de Pesca, Redes de Computadores e Saneamento foram ofertados apenas uma vez no municipio de Altamira e tiveram um número expressivo de alunos evadidos, sendo $60,4 \%$ no total dos três cursos, dos quais 50,0\% de evadidos no curso de Pesca, 80,0\% no curso de Redes de Computadores e 52,5\% no curso de Saneamento. Esse fator pode se justificar pela descontinuidade do curso, o que impossibilitaria ao aluno reprovado a oportunidade de reingresso ao curso.

Figura 3 - Percentual de alunos evadidos e concluidos por curso ofertado pelo IFPA campus Altamira de 2010 a 2016

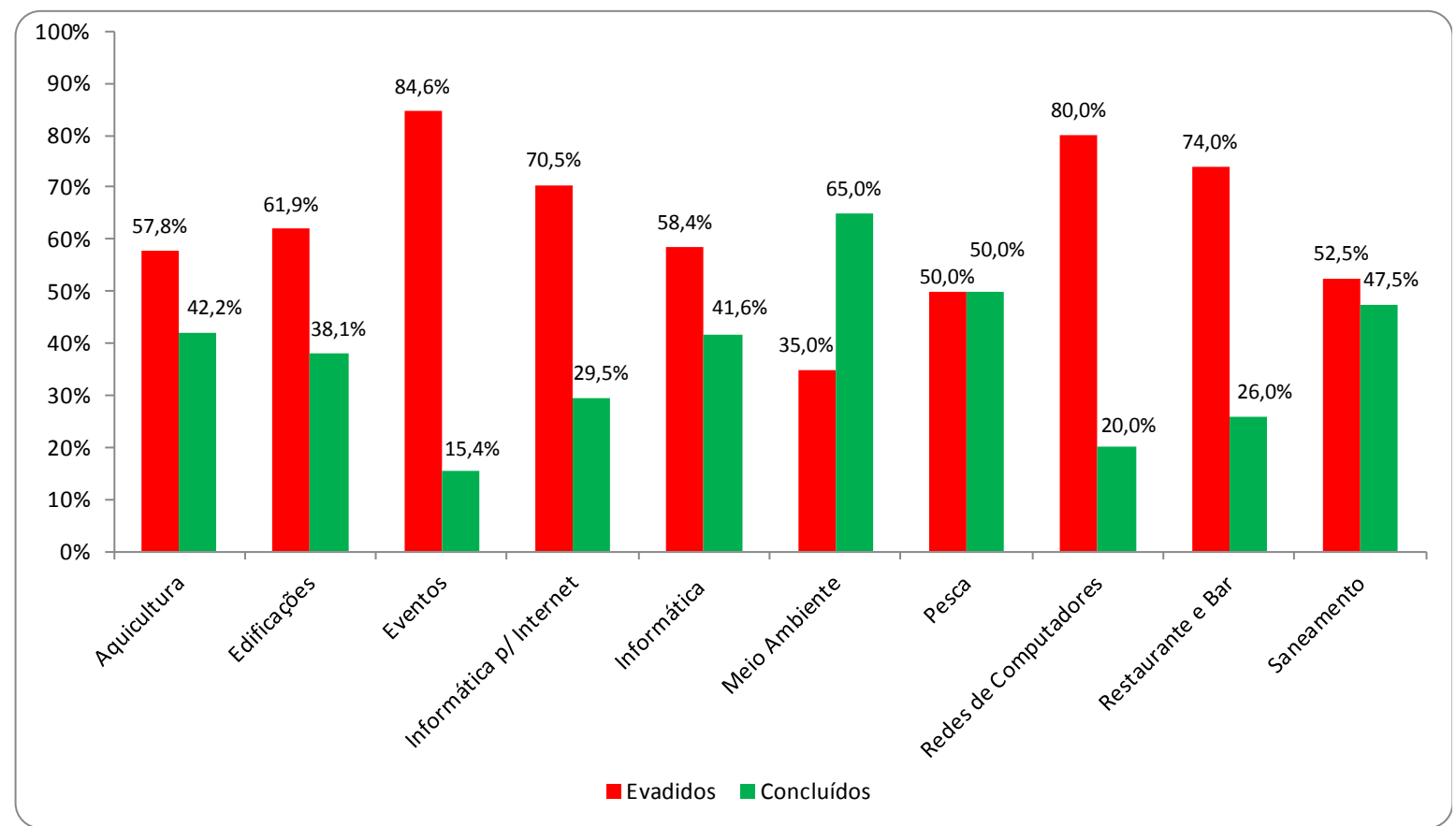

Fonte: Elaborado pelas autoras (2019).

O curso que teve a menor taxa de evasão em sua oferta foi o curso técnico em Meio Ambiente, com 35,0\% de alunos evadidos. Os cursos com maior taxa de evasão foram os cursos técnicos em Eventos, com 84,6\%, em Redes de Computadores, com 80,0\%, em Restaurante e Bar, com 74,0\% e em Informática para Internet, com 70,5\%.

Bastos e Gomes (2014) sinalizam que se torna necessário que, os alunos, ao se inscreverem para concorrer a uma vaga no ensino técnico, tenham um maior esclarecimento sobre os cursos oferecidos, para que ao ingressarem no curso não o abandonem por falta de interesse e desmotivação.
Dore e Luscher (2011), indicam que a identificação precoce dos problemas que causam a evasão, torna-se possivel a realização de um acompanhamento individual com os estudantes que estão em situação de risco de evadir, a fim de proporcionar a estes estudantes êxito escolar.

No periodo pesquisado, a evasão alcançou um percentual total de 61,6\%, um número expressivo que demonstra a necessidade da instituição em ter um olhar especial com as questões relacionadas à permanência e evasão, com ações que possibilitem o êxito estudantil. Dos 925 alunos ingressantes no periodo pesquisado, apenas 355 tiveram 
êxito estudantil com a finalização do curso, o que representa 38,4\% do total de alunos ingressantes. O número de casos de evasão no IFPA campus Altamira pode ser classificado como um problema social e político que requer uma soma de esforços em prol da melhoria da educação ofertada.

Em todos os anos, o percentual de evasão foi igual ou superior a 50,0\%, tendo a evasão fortemente acentuada no ano de 2015, quando o campus ofertou somente os cursos técnicos em Edificações e em Informática, com ingresso de duas turmas para cada curso, sendo registrados, $79,3 \%$ de evasão. A menor evasão foi no ano de 2016, com 50,0\% dos estudantes.

Figura 4 - Percentual de alunos evadidos e concluidos por ano de oferta, no período de 2010 a 2016 no IFPA campus Altamira

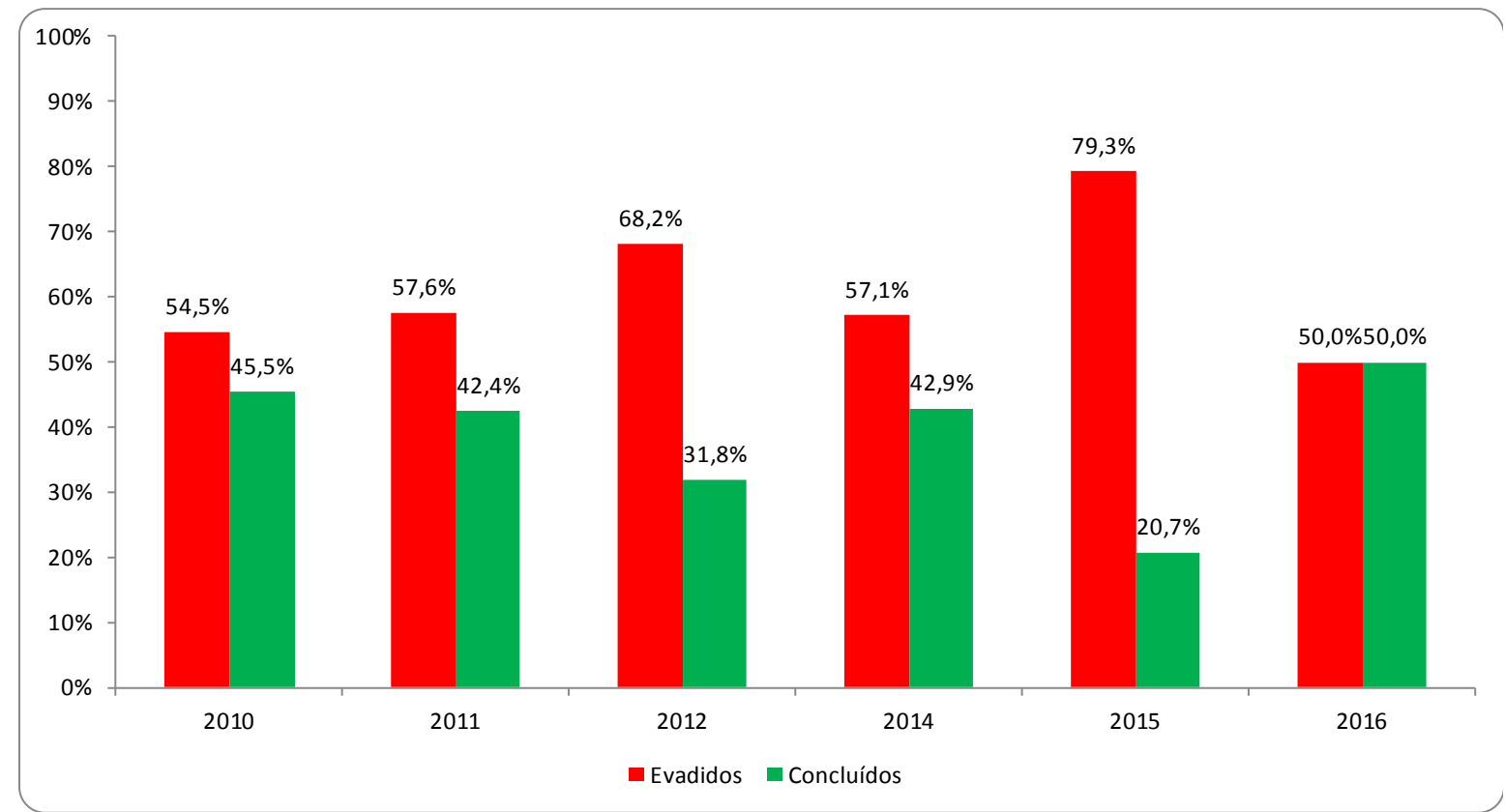

Fonte: Elaborado pelas autoras (2019).

A partir do período letivo de 2012, percebe-se a evolução da evasão escolar, notando-se alarmantes índices de evasão 68,2\%, 57,1\% e 79,3\%. Todavia, houve um decréscimo em 2016, quando o percentual atingiu 50\%.

Em virtude do exposto, vale ressaltar que esses dados podem ter influenciado o planejamento de cursos no campus Altamira, no período de 2012 a 2016. Isso porque a gestão acadêmica avalia o cenário sobre a taxa de evasão obtida nos anos anteriores, para assim continuar a oferta de novas vagas.

Não obstante, parte desses alunos ingressaram no ensino técnico, possivelmente, com o objetivo de conseguir uma boa formação que lhes proporcionasse a inserção rápida no mercado de trabalho, porém, conforme afirma Meira (2015) ao se depararem com uma realidade de um mercado que não atende às expectativas, o aluno se desmotiva e abandona o curso. Dessa forma, Araújo e Santos (2012), indicam que os fatores associados ao mercado de trabalho como a conjuntura econômica, o reconhecimento da carreira, a desvalorização da profissão e o desemprego podem influenciar a decisão do aluno de abandonar o estudo. Assim, ações que garantam uma inserção dos alunos em estágios e outras práticas profissionais podem auxiliar na permanência e conclusão do curso.

Um dos fatores identificados nesse estudo como principal causa da evasão está a dificuldade em conciliar trabalho e estudo (MACHADO, 2009; FERREIRA, 2013; BASTOS; GOMES, 2014; MEIRA, 2015; FIGUEIREDO; SALLES, 2017). Muitos alunos são responsáveis pelo sustento de suas familias e não conseguem prosseguir com os estudos, tendo que optar pelo trabalho ao invés da conclusão do curso. 
Nesse sentido, Meira (2015) sinaliza como uma ação imprescindivel para que o processo de ensino aprendizagem aconteça de maneira satisfatória, é o apoio contínuo da equipe multidisciplinar, no intuito de detectar necessidades acadêmicas e sociais dos alunos, além de realizar intervenções rápidas a partir da identificação dos problemas, com a finalidade de evitar a evasão.

Com intuito de proporcionar o acesso, permanência e êxito estudantil no âmbito do IFPA, foi aprovada em 8 de setembro em 2016, a Resolução n. ${ }^{\circ} 147$ que regulamenta a política de assistência estudantil na instituição.

O objetivo da assistência ao estudante, além da melhoria do desempenho acadêmico, é também contribuir para a diminuição da retenção e evasão decorrente da falta de recursos para custear os estudos daqueles alunos em vulnerabilidade socioeconômica.

Dessa forma, por meio da assistência estudantil foi implantado o Programa de Assistência Estudantil (PAE) com a oferta, por meio de editais de seleção, de bolsas de moradia estudantil, alimentação, transporte e apoio pedagógico (IFPA, 2016). Não há dados de pesquisa sobre a criação do PAE no campus Altamira e se sua efetivação tem contribuído para atenuar a evasão, temática que será abordada em pesquisas futuras.

Essas ações podem gerar efeitos positivos na instituição, porém para que a permanência e o êxito estudantil aconteçam de maneira satisfatória, torna-se necessário a mobilização de todos os profissionais envolvidos no processo de ensino e aprendizagem. Assim, para que trabalhem em conjunto na busca por estratégias que levem a diminuição da evasão. Isso inclui, ainda a inovação no planejamento da instituição, no repensar do seu papel formador e revisão de seus projetos.

Outro aspecto que não pode deixar de ser mencionado é a importância do acompanhamento familiar. A familia e a escola, de acordo com Lahire (1993), devem ter uma relação de interdependência no acompanhamento e apoio ao estudante. A falta de incentivo da família e da escola corroboram com essa ideia para que o estudante decida pela evasão (SILVA FILHO; ARAÚJO, 2017).
Entretanto, para refletir acerca das causas da evasão torna-se de grande importância ouvir os alunos evadidos e a equipe de profissionais do campus e categorizar as causas da evasão com a finalidade de auxiliar na implantação políticas, ações e programas eficientes que promovam a permanência e êxito estudantil.

\section{Considerações finais}

Neste estudo o objetivo foi identificar os índices de evasão nos cursos técnicos subsequentes presenciais ofertados pelo IFPA campus Altamira no período de 2010 a 2016.

Foi identificado um elevado índice de evasão que variara entre $35,0 \%$ a $84,6 \%$ entre os cursos ofertados e um total $61,6 \%$ de evasão no periodo pesquisado. Esse cenário indica a necessidade de empenho coletivo entre escola e família no combate à evasão.

Na literatura é indicado que uma das principais causas que tem levado o estudante a evadir nesse contexto é a dificuldade em conciliar trabalho e estudo, não havendo pesquisas publicadas que analisam as causas da evasão no campus Altamira.

Programas de assistência estudantil implantados podem contribuir para a permanência dos estudantes, contudo não há ainda pesquisas publicadas que indiquem a relação implantação de programas de assistência ao estudante e evasão no campus.

Dessa forma, estudos relacionados às causas da evasão e a relação evasão - programas de assistência estudantil são recomendados, pois juntamente com estudos quantitativos poderão contribuir para a discussão e possivel implantação de políticas especificas para o combate à evasão no âmbito do IFPA campus Altamira.

\section{Referências}

ARAÚJO, Cristiane Ferreira; SANTOS, Roseli Albino dos. A educação profissional de nível médio e os fatores internos/externos às instituições que causam a evasão escolar. In: INTERNATIONAL CONGRESS ON UNIVERSITY - INDUSTRY COOPERATION, 4., 2012, Taubaté. Anais [...]. Taubaté: Universidade de Taubaté, 2012. Disponivel em: https://silo.tips/download/a-educaao-profissional-de-nivel-medio-e-os-fatores-internos-externos-as-institui. Acesso em: 25 jun. 2019. 
ARAUJO, Ronaldo Marcos de Lima; FRIGOTTO, Gaudêncio. Práticas pedagógicas e ensino integrado. Revista Educação em Questão, Natal, v. 52, n. 38, p. 61-80, 2015. Disponivel em: https://periodicos.ufrn.br/educacaoemquestao/article/viewFile/7956/5723. Acesso em: 10 out. 2019

BASTOS, Oliver Guimarães Armando; GOMES, Carlos Francisco Simões. A evasão escolar no Ensino Técnico: entendendo e enfrentando as dificuldades - Um estudo de caso do CEFET-RJ. Educação e Cultura Contemporânea, Rio de Janeiro, v. 13, n. 32, p. 217- 234. 2017 Disponivel em: https://www.researchgate.net/ publication/309592799_A_evasao_escolar_no_Ensino_Tecnico_um_estudo_de_caso_do_CEFET-RJ. Acesso em: 25 maio 2019.

BRASIL. Poder Executivo Federal. Decreto $n^{\circ} 7.566$, de 23 de setembro de 1909. Crêa nas capitaes dos Estados da Republica Escolas de Aprendizes Artifices, para o ensino profissional primario e gratuito. Diário Official, Rio de Janeiro, RJ, p. 675, 26 set. 1909. Disponivel em: https:// www2.camara.leg.br/legin/fed/decret/1900-1909/ decreto-7566-23-setembro-1909-525411-publicacaooriginal-1-pe.html. Acesso em: 10 jun. 2019.

BRASIL. Lei n 378, de 13 de janeiro de 1937. Dá nova organização ao Ministério da educação e Saúde Pública. Diário Official, Rio de Janeiro, RJ, p. 1210, 15 jan. 1937a Disponivel em: http://www2.camara.leg.br/legin/fed/ lei/1930-1939/lei-378-13-janeiro-1937-398059-publicacaooriginal-1-pl.html. Acesso em: 25 jun. 2019.

BRASIL. [Constituição (1937)]. Constituição dos Estados Unidos do Brasil. Rio de Janeiro, RJ: Presidência da República, 10 nov. 1937. Disponivel em: http://www. planalto.gov.br/ccivil_03/constituicao/constituica037. htm Acesso em: 20 jun. 2019.

BRASIL. Decreto n 4.127, de 25 de fevereiro de 1942 Estabelece as bases de organização da rede federal de estabelecimentos de ensino industrial. Diário Oficial da União: seção 1, Rio de Janeiro/RJ, p. 2957, 27 fev. 1942. Disponivel em: http://www2.camara.leg.br/legin/ fed/declei/1940-1949/decreto-lei-4127-25-fevereiro-1942-414123-publicacaooriginal-1-pe.html. Acesso em: 26 jun. 2019

BRASIL. Lei n 4.024, de 20 de dezembro de 1961. Fixa as Diretrizes e Bases da Educação Nacional. Diário Oficial da União: seção 1, Brasilia, DF, p. 11429, 27 dez. 1961. Disponivel em: http://wwww2.camara.leg.br/legin/fed/ lei/1960-1969/lei-4024-20-dezembro-1961-353722-publicacaooriginal-1-pl.html. Acesso em: 20 jun. 2019.

BRASIL. Lei $\mathbf{n}^{\circ} \mathbf{6 . 5 4 5}$, de 30 de junho de 1978. Dispõe sobre a transformação das Escolas Técnicas Federais de Minas Gerais, do Paraná e Celso Suckow da Fonseca em Centros Federais de Educação Tecnológica e dá outras providências. Disponivel em: http://wwww2.camara.leg.br/legin/fed/lei/1970-1979/lei-6545-30-junho-1978-366492-normaatualizada-pl.html. Acesso em: 19 jun. 2019

BRASIL. Lei $\mathbf{n}^{\circ} \mathbf{8 . 9 4 8}$, de 8 de dezembro de 1994 Dispõe sobre a instituição do Sistema Nacional de Educação Tecnológica e dá outras providências. BrasíLia, DF: Presidência da República, 1994. Disponivel em: http://www.planalto.gov.br/ccivil_03/LEIS/L8948.htm. Acesso em: 27 jun. 2019.
BRASIL. Lei $n^{\circ}$ 9.394, de 20 de dezembro de 1996. Estabelece as diretrizes e bases da educação nacional. Brasilia, DF, 1996. Disponivel em: http://Ww/w. planalto.gov. br/ccivil_03/LEIS/L9394.htm. Acesso em: 28 jun. 2019.

BRASIL. Lei $\mathbf{n}^{\circ} \mathbf{1 1 . 7 4 1}$, de $\mathbf{1 6}$ de julho 2008. Altera dispositivos da Lei no 9.394, de 20 de dezembro de 1996, que estabelece as diretrizes e bases da educação nacional, para redimensionar, institucionalizar e integrar as ações da educação profissional técnica de nivel médio, da educação de jovens e adultos e da educação profissional e tecnológica. Brasilia, DF, 2008a. Disponivel em: http://www.planalto.gov.br/ ccivil_03/_Ato2007-2010/2008/Lei/L11741.htm. Acesso em 25 jun. 2019.

BRASIL. Lei ${ }^{\circ} \mathbf{1 1 . 8 9 2}$, de 29 de dezembro de 2008. Institui a Rede Federal de Educação Profissional, Científica e Tecnológica, cria os Institutos Federais de Educação, Ciência e Tecnologia, e dá outras providências. Brasilia, DF, 2008b. Disponivel em: http://www.planalto.gov.br/ ccivil_03/_ato2007-2010/2008/lei/L11892.htm. Acesso em: 22 maio 2019.

BRASIL. Decreto n 7.234, de 19 de julho de 2010 Dispõe sobre o Programa Nacional de Assistência Estudantil - PNAES. Brasília, DF, 2010. Disponivel em: http:// WwW.planalto.gov.br/ccivil_03/_ato2007-2010/2010/ decreto/d7234.htm. Acesso em: 11 nov. 2019

BRASIL. Ministério da Educação. Secretaria de Educação Profissional e Tecnológica. Documento orientador para a superação da evasão e retenção na rede federal de educação profissional, científica e tecnológica. Brasilia, DF: Ministério da Educação, 2014. Disponivel em: http://portal.mec.gov.br/index.php?option=com docman\&view=download\&alias=110401-documento-orientador-evasao-retencao-vfinal\&category slu$\mathrm{g}=$ abril-2019-pdf\&ltemid=30192Acesso em: 5 set. 2019.

BRASIL. Ministério da Educação. Expansão da Rede Federal. 2016a. Disponivel em: http://redefederal. mec.gov.br/expansao-da-rede-federal. Acesso em: 22 nov. 2019

BRASIL. Ministério da Educação. Centenário da rede Federal de Educação Profissional e Tecnológica. Brasilia, DF, 2016b. Disponivel em: http://portal.mec. gov.br/setec/arquivos/centenario/historico_educacao_profissional.pdf. Acesso em: 17 nov. 2019

BRASIL. Ministério da Educação. Secretaria de Educação Profissional e Tecnológica. Manual do Sistema Nacional de Educação Tecnológica. Brasilia, DF, 2016c. Disponivel em: http://sitesistec.mec.gov.br/images/arquivos/pdf/Guia_Sistec_IF_v2.2_05072016.pdf. Acesso em: 20 nov. 2019

BRAZOROTTO, Cintia Magno. Quem são os estudantes do Ensino Médio profissionalizante no Brasil e na Alemanha? In: COLÓQUIO NACIONAL, 4.; COLÓQUIO INTERNACIONAL, 1., 2017, Natal. Anais [...]. Natal: Instituto Federal do Rio Grande do Norte, 2017. Tema: Produção do conhecimento em educação profissional. Disponível em: https://ead.ifrn.edu.br/coloquio/anais/2017/ trabalhos/eixo1/E1A51.pdf. Acesso em: 22 out. 2019. 
CASTRO, Luciana Paula Vieira de; MALACARNE, Vilmar. Conceituando a evasão escolar no Brasil. In: ENCONTRO INTERNACIONAL DE PRODUÇÃO CIENTÍFICA, 7., Maringá, 2011. Anais [...]. Maringá: Editora CESUMAR, 2011. Disponivel em: http://www.cesumar.br/prppge/ pesquisa/epcc2011/anais/luciana_paula_vieira_castro1.pdf. Acesso em: 30 out. 2019

CAMPOS, Marcelo Mallet Siqueira. A expansão da rede federal de educação profissional, técnica e tecnológica no período 2003-2014: uma análise a partir da abordagem das capacitações. Revista Economia e Desenvolvimento, Santa Maria, v. 28, n. 2, p. 497-516, jul./ dez. 2016. Disponivel em: https://periodicos.ufsm.br/ eed/article/view/26166/pdf. Acesso em: 11 nov. 2019

DIRETORES de ensino e membros das CPE's do IFPA participam do I Seminário sobre Permanência e Êxito. In: Instituto Federal do Pará. Belém, 11 dez. 2017. Disponivel em: https://Www.ifpa.edu.br/component/ content/article?id=690. Acesso em: 10 nov. 2019.

DORE, Rosemary; LUSCHER, Ana Zuleima. Permanência e evasão na educação técnica de nivel médio em Minas Gerais. Cadernos de Pesquisa, São Paulo, v. 41, n. 144, p. 770-89, dez. 2011. http://doi.org/10.1590/ S0100-15742011000300007. Acesso em 23 ago. 2019.

INSTITUTO FEDERAL DO PARÁ. Plano de Desenvolvimento Institucional 2014-2018 (Revisado). Instituto Federal de Educação, Ciência e Tecnologia do Pará, Belém/PA 2014. Disponivel em: https://www.ifpa.edu.br/ documentos-institucionais/0000/docs-inst/4032-pdi-2014-2018-revisado/file. Acesso em: 27 set. 2019.

INSTITUTO FEDERAL DO PARÁ, CONSUP. Resolução $\mathbf{n}^{\circ}$ 111/2015, de 19 de agosto de 2015. Cria áreas de abrangência por Câmpus. Belém, PA, 2015. Disponivel em:

https://sigp.ifpa.edu.br/sigrh/downloadArquivo?idArquivo $=24308 \& \mathrm{key}=3 \mathrm{~d} 6 \mathrm{obd} 48 \mathrm{~d} 6 \mathrm{e} 8 \mathrm{~d} 3 \mathrm{~b} 16 \mathrm{f} 7 \mathrm{a}-$ 522903 c8b977 Acesso em 20 nov. 2019.

INSTITUTO FEDERAL DO PARÁ. CONSUP. Resolução $n^{\circ}$ 147/2016, de 8 de setembro de 2016. Regulamenta a Politica de Assistência

Estudantil no Instituto Federal de Educacao, Ciencia e Tecnologia do Pará (IFPA). Belém/PA, 2016. Disponivel em: http://proen.ifpa.edu.br/documentos-1/13-resolucoes-do-consup/resolucao-do-consup/2016-3/ 1469-resolucao-n-147-2016/file. Acesso em: 22 nov. 2019.

INFORME estatístico do MEC revela melhoria do rendimento escolar. In: Instituto Nacional de Estudos e Pesquisas Educacionais Anísio Teixeira. Brasilia, DF, 1998. Disponivel em: http://inep.gov.br/artigo/-/ asset_publisher/B4AQVgzFY7BV/content/informe-estatistico-do-mec-revela-melhoria-do-rendimento-escolar/21206. Acesso em: 29 jun. 2019.

FALCÃO, Gabriela Lins; SANSIL, Cláudia da Silva Santos. Desafios Curriculares e Evasão na Educação Profissional de Nivel Médio. In: Espaço do currículo, João Pessoa, PB. v. 7. n. 1, p. 64-75, jan./abr. 2014. Disponivel em: http://www.periodicos.ufpb.br/ojs/index.php/rec/ article/view/19410/10755. Acesso em: 27 jun. 2019.
FERREIRA, Fabrício Alves. Fracasso e evasão escolar. Brasil Escola, 2013. Disponivel em: https://educador. brasilescola.uol.com.br/orientacao-escolar/fracasso-evasao-escolar.htm. Acesso em: 26 jun. 2019.

FIGUEIREDO. Natália da Silva. SALLES, Denise Medeiros Ribeiro. Educação Profissional e evasão escolar em contexto: motivos e reflexões. Ensaio: aval. pol. públ. Educ., Rio de Janeiro, v. 25, n. 95, p. 356-392, 2017. Disponivel em: http://www.scielo.br/scielo.php?pi$\mathrm{d}=\mathrm{S} 010440362017000200356 \&$ script=sci_abstract\&tlng=pt. Acesso em: 20 jun. 2019.

GIL, Antônio. Carlos. Como elaborar projetos de pesquisa. 6. ed. São Paulo: Atlas, 2010.

LAHIRE, Bernard. Sucesso escolar nos meios populares: As razões do improvável. São Paulo: Ática,1997.

MACHADO, Márcia Rodrigues. A evasão nos cursos de agropecuária e informática/nível técnico da Escola Agrotécnica Federal de Inconfidentes (MG, 2002 a 2006). 2009. 131 p. Dissertação (Mestrado em Educação) - Faculdade de Educação da UNB, Brasília, DF, 2009. Disponivel em: http://WwW.repositorio.unb. br/bitstream/10482/8676/1/2009_MarciaRodriguesMachado.pdf. Acesso em: 25 jun. 2019.

MEIRA, Cristiane Araújo. A evasão escolar no ensino técnico profissionalizante: um estudo de caso no Campus Cariacica do Instituto Federal do Espírito Santo. 2015. 118 f. Dissertação (Mestrado Profissional em Gestão Pública) - Universidade Federal do Espírito Santo, Centro de Ciências Jurídicas e Econômicas. Espírito Santo. 2015. Disponivel em http://portais4.ufes.br/pos$\mathrm{grad} /$ teses/tese_9068_Disserta\%E7\%E30\%20Final\%20 \%20Cristiane\%20Meira.pdf. Acesso em: 20 jun. 2019.

SILVA FILHO, Raimundo Barbosa, ARAÚJO, Ronaldo Marcos de Lima. Evasão e abandono escolar na educação básica no Brasil. Educação Por Escrito, Porto Alegre, v. 8, n. 1, p. 35-48, jan./jun. 2017. Disponivel em: http:// revistaseletronicas.pucrs.br/ojs/index.php/porescrito/ article/view/24527/15729. Acesso em: 23 out. 2019.

SOUZA, Juarina Ana da Silveira. Permanência e evasão escolar: um estudo de caso em uma instituição de ensino profissional. 2014, 152 p. Dissertação (Mestrado Profissional em Educação) - Universidade Federal de Juiz de Fora, Faculdade de Educação/CAEd. Programa de Pós-Graduação em Educação, Juiz de Fora, MG. 2014. Disponivel em: http://Www.mestrado.caedufjf. net/permanencia-e-evasao-escolar-um-estudo-de-caso-em-uma-instituicao-de-ensino-profissional/. Acesso em: 27 nov. 2019.

\section{Larici Keli Rocha Moreira}

Especialista em Politicas Educacionais e Saberes Docentes pela Universidade Federal do Pará (UFPA), em Altamira, PA, Brasil; professora do Instituto Federal de Educação, Ciência e Tecnologia do Pará (IFPA), em Altamira, PA, Brasil. 


\section{Maria de Fátima Matos de Souza}

Doutora em Educação Escolar pela Universidade Estadual Paulista (UNESP), em Araraquara, SP, Brasil. Professora da Universidade Federal do Pará (UFPA), Altamira, PA, Brasil.

\section{Regina Celi Alvarenga de Moura Castro}

Mestre em Educação pela Universidade Federal de Viçosa (UFV), em Viçosa, MG, Brasil. Professora da Universidade Federal do PA (UFPA), Campus Altamira, em Altamira, Pará.

\section{Endereço para correspondência}

Larici Keli Rocha Moreira

Instituto Federal do Pará

Rod. Ernesto Acioly, s/n

Estrada do Forte, Colina, 6837-.001

Altamira, PA, Brasil

Maria de Fátima Matos de Souza

Universidade Federal do Pará

Trav. da Estrela, 3553

Bairro do Marco, 66080-474

Belém, PA, Brasil

Regina Celi Alvarenga de Moura Castro

Universidade Federal do Pará

Rua Coronel José Porfírio, 2515, Prédio Administrativo II São Sebastião, 68370-001

Altamira, PA, Brasil

Os textos deste artigo foram revisados pela Poá Comunicação e submetidos para validação do(s) autor(es) antes da publicação 